\title{
UMA ANÁLISE DO NOMINALISMO DE AVESTRUZ
}

\author{
Valdetonio Pereira de Alencar ${ }^{1}$ \\ Universidade Federal do Cariri (UFCA) \\ (iD) https://orcid.org/0000-0001-8192-9396 \\ E-mail: valdetonio.alencar@ufca.edu.br
}

\section{RESUMO:}

O objetivo deste artigo é analisar criticamente o Nominalismo de Avestruz. Em primeiro lugar, apresento as teses principais dessa solução, bem como analiso se ela deve ser considerada uma solução para o problema dos universais. Apesar de argumentar que essa teoria não considera o problema dos universais um pseudoproblema, levanto uma série de problemas contra esta posição. Em geral, levantei três críticas principais. A primeira concerne ao critério quantificacional. Argumentei que esse critério apresenta problemas se interpretado como critério ontológico. Entendo que esse critério não pode ser utilizado para solucionar o problema dos universais. A segunda crítica concerne ao problema do regresso. O Nominalismo de Avestruz possui como um dos eixos centrais de sua argumentação o problema do regresso ao infinito. Argumentei, contudo, que tal problema não afeta todas as soluções relacionais. Por último, exploro uma crítica externa. Analiso a resposta de Melia ao problema dos truthmakers, levantado por Rodriguez-Pereyra.

PALAVRAS-CHAVE: Nominalismo; Comprometimento Ontológico; Regresso ao infinito.

\section{A INQUIRY TO OSTRICH NOMINALISM}

\begin{abstract}
:
In this paper, I discuss the Ostrich Nominalism. At first, I attempt a clarification of main theses of Devitt. In addition, I analyze whether this kind of nominalism can be considered a solution to the problem of universals. After arguing that this theory does not consider the problem of universals a pseudoproblem, I discuss three criticisms against Ostrich Nominalism. Ontological commitment is the topic of first criticism. I argue that this notion does not provide a sufficient ontological criterion. Later, I analyze the regress infinite argument. The ostrich nominalist argues that all relational solutions to the problem of universals have this problem. However, I advocate that infinite regress argument does not refute all relational solutions. Finally, I analyze an external criticism. RodriguezPereyra maintains that ostrich nominalism cannot be understood as a truthmaking theory.
\end{abstract}

KEYWORDS: Nominalism; Ontological Commitment; Infinite Regress.

\footnotetext{
1 Doutor em Lógica e Metafísica pela Universidade Federal do Rio de Janeiro (UFRJ), Rio de Janeiro - RJ, Brasil. Professor da Universidade Federal do Cariri (UFCA), Juazeiro do Norte - CE, Brasil.

ALENCAR, Valdetonio Pereira de. Uma análise do nominalismo de avestruz. Griot : Revista de Filosofia, Amargosa-BA, v.18, n.2, p.435-447, dezembro, 2018. 
O problema dos universais é um problema metafísico que diz respeito ao estatuto ontológico das propriedades. Soluções para esse problema que rejeitam universais como categorias ontológicas fundamentais são denominadas "Nominalismo". De maneira oposta, soluções realistas consideram que universais constituem uma categoria ontológica fundamental para explanar uma série de fenômenos (semelhança entre diferentes particulares, por exemplo). Há, contudo, outras maneiras de classificar as soluções para o problema acima. Armstrong (1978, p. 28) distingue, de um ponto de vista epistemológico, dois tipos de soluções para o problema dos universais: as objetivistas e as subjetivistas. Uma solução subjetivista para o problema dos universais caracteriza-se por explanar propriedades fazendo referência a sistemas de classificação do ser humano. Nesse caso, propriedades seriam meras projeções nossas. Armstrong identifica duas formas de Nominalismo subjetivista: o Nominalismo de Predicado e o Nominalismo de Conceito. Uma solução objetivista para o problema dos universais caracteriza-se por explanar as propriedades de um objeto sem nenhuma referência a classificações humanas, isto é, propriedades não seriam meras projeções humanas. Todo Realismo a respeito de universais constituiria uma solução objetivista para o problema, pois, se universais existem, então eles independem do representar humano. Além disso, há algumas soluções nominalistas que são objetivistas, segundo Armstrong. São os casos do Nominalismo de Classe e do Nominalismo de Semelhança. A distinção entre soluções subjetivistas e objetivistas aponta um aspecto interessante do debate sobre propriedades. Contudo, é fato que a classificação mais importante para esse debate é a distinção entre nominalistas e realistas.

As duas formas acima de classificar as soluções para o problema dos universais não esgotam o debate. Além da divisão entre realistas e nominalistas e da entre subjetivistas e objetivistas, existe pelo menos mais uma terceira maneira de classificar as posições neste debate. Podemos dividir as soluções entre relacionais e não relacionais, para o problema dos universais. Uma solução relacional postula uma relação ao analisar o fato de um particular possuir uma propriedade. Assim, dado o fato de que $a$ é $F$, temos as seguintes análises relacionais concorrentes:

(1) Nominalismo de Predicado: $a$ é $F$ porque/em virtude de $a$ cair sob o predicado "F".

(2) Nominalismo de Conceito: $a$ é $F$ porque/em virtude de $a$ cair sob o conceito $F$.

(3) Nominalismo de Classe: $a$ é $F$ porque/em virtude de $a$ pertencer à classe dos Fs;

(4) Nominalismo de Semelhança: $a$ é $F$ porque/em virtude de $a$ ser semelhante aos Fs;

(5) Realismo: $a$ é $F$ porque/em virtude de $a$ ser uma instância do universal F;

(6) Teoria de Tropos: $a$ é $F$ porque/em virtude do tropo $f .{ }^{23}$

\footnotetext{
2 Cada uma dessas soluções pode apresentar maneiras diferentes de realizar esta análise. Por exemplo, o Nominalismo de Semelhança apresenta a versão aristocrática (Price) e a versão igualitária (Rodriguez-Pereyra). Independente das variações internas, essas seis soluções para o problema dos universais introduzem alguma relação para analisar o fato de um particular possuir uma propriedade.

${ }^{3}$ Diferentes teorias de tropos tentaram solucionar o problema dos universais postulando relações diferentes. Há basicamente dois tipos de teorias: o nominalismo de classe de tropos e a teoria de tropos pura. A primeira postula a relação de pertencer $a$, enquanto a segunda postula a relação de semelhança, a fim de solucionar o problema dos universais.
}

ALENCAR, Valdetonio Pereira de. Uma análise do nominalismo de avestruz. Griot : Revista de Filosofia, 
Uma solução não relacional para o problema não postula nenhuma relação para explanar o fato de um particular possuir uma propriedade. Existe apenas uma solução não relacional para o problema dos universais: o Nominalismo de Avestruz. O objetivo deste artigo é discutir essa posição. Em primeiro lugar, apresento as teses principais dessa solução, bem como analiso se ela deve ser considerada uma solução para o problema dos universais. Em segundo lugar, discuto o argumento central do nominalista de avestruz contra as soluções relacionais para o problema dos universais: o problema do regresso. Além disso, analiso a crítica de RodriguezPereyra ao nominalista de avestruz.

\section{O Nominalismo de avestruz é uma solução para o problema dos universais?}

O termo "Nominalismo de Avestruz" foi introduzido de maneira pejorativa por Armstrong (1978, p. 16). Segundo este, um nominalista de avestruz sustenta o Nominalismo enquanto ignora o problema dos universais, pois não acredita que seja necessário analisar fatos da forma $a$ é $F$. Essa posição seria como um avestruz que ignora um problema ao colocar a cabeça debaixo da terra. Ele identifica que Quine teria defendido o Nominalismo de Avestruz. Quine (1961, p. 9-10) considera que o One Over Many constitui uma maneira enganosa de falar sobre propriedades. Podemos admitir que particulares sejam vermelhos, mas isso não implica que eles tenham algo em comum. Ocorre que a palavra "vermelho" aplica-se corretamente aos particulares que são vermelhos, mas não há nenhuma entidade em adição aos particulares que seja a referência dessa palavra. Que um particular é vermelho é um fato último e irredutível, segundo Quine.

Uma solução para o problema dos universais consiste em fornecer uma análise de fatos da forma $a$ é $F$. Contudo, se o nominalista de avestruz não fornece uma análise do fato acima, então ainda podemos considerar essa teoria como uma solução para o problema dos universais? Em primeiro lugar, não é totalmente evidente que tal posição não forneça uma análise de fatos da forma a é $F$. Para entender esse aspecto, precisamos entender melhor o que é uma análise desses fatos. Em todas as análises (1-6), utilizamos a expressão "porque". Se levarmos em consideração o uso cotidiano deste termo, então o uso dessa expressão nas análises acima pode levar a alguma confusão. Uma maneira bem comum de usar "porque" é como explicação causal. Por exemplo, a água ferve porque a temperatura aumentou. Contudo, não parece ser o sentido de explanação causal que as análises acima afirmam. Seria, nesse sentido, trivial afirmar que Sócrates é humano porque é uma instância do universal humanidade. Assim, precisamos entender melhor o que significa fornecer uma análise do fato a é $F$. Entendo que fornecer uma análise ontológica do fato a é $F$ consiste em asserir quais tipos de entidades fundamentais compõem esse fato. $O$ nominalista vai dizer que esse fato é composto apenas por particulares; o realista vai advogar que o mesmo fato é composto por universais. Neste sentido de análise, o nominalista de avestruz fornece uma análise do fato acima. Segundo ele, o fato a é $F$ é constituído exclusivamente pelo particular $a$. É evidente que quando você tenta formular o nominalista de avestruz como fornecendo uma explanação de a ser $F$, parece que ele não possui uma análise. A análise explanatória desse nominalista seria:

ALENCAR, Valdetonio Pereira de. Uma análise do nominalismo de avestruz. Griot : Revista de Filosofia, 
(7) a é $F$ porque $a$ é $F$.

Existe, de fato, uma análise em (7)? Alguns poderiam dizer que sim, mas essa análise é circular. Se entendermos a análise em (7) como uma análise ontológica da maneira como caracterizei acima, podemos defender que há uma análise não circular em (7). $O$ fato $a$ é $F$ é mooreano, isto é, é um fato inegável e pré-analítico. Fato, neste contexto, não é uma categoria ontológica fundamental. Em sua análise, o nominalista de avestruz aceita particulares concretos como entidade ontológica fundamental. $O$ que esse nominalista não faz é considerar que a propriedade $F$ constitui uma entidade separada dos particulares concretos, isto é, que são universais. Que particulares concretos (entendidos enquanto categoria ontológica fundamental) possuem propriedades é um aspecto primitivo do mundo.

Podemos comparar a ontologia do Nominalismo de Avestruz com outras formas de Nominalismo. Melia tem muita clareza sobre o caráter parcimonioso do seu Nominalismo. Ele denomina seu Nominalismo de Avestruz de "Nominalismo Sensível" (2005, p. 67). Para o nominalista sensível, o mundo é constituído apenas por particulares concretos. Esse nominalista procura evitar vários tipos de entidades: universais, classes, estado de coisas, tropos e possibilia.

Devitt (2010) foi quem inicialmente tentou resgatar o Nominalismo de Avestruz de Quine. Primeiro, ele procurou caracterizar de uma maneira não pejorativa essa posição. Sustentar o Nominalismo enquanto rejeita o argumento do One Over Many não é ser um nominalista de avestruz, pois esse nominalista não pode ignorar um problema que não existe. Para mostrar que esse problema não existe, Devitt recorreu ao critério de comprometimento ontológico de Quine. Para analisar o fato de $a$ ser $F$, precisamos responder à seguinte questão: qual o comprometimento ontológico de "a é F"? Quine possui um critério para responder a essa questão sem postular universais:

- "a é F" é verdadeiro se, e apenas se, há um x tal que "a" designa x e "F" aplicase a x.

Não devemos, contudo, confundir o Nominalismo de Avestruz com o Nominalismo de Predicado. Este pretende analisar propriedades através de predicados; o Nominalismo de Avestruz não possui tal intuito. Propriedades são aspectos primitivos de particulares concretos no mundo. $O$ ponto desta forma de Nominalismo consiste em indicar que sentenças da forma "a é F" podem ser parafraseadas de uma forma que não nos comprometam com universais.

A estratégia do nominalista de avestruz é similar à do nominalista de semelhança para solucionar o problema dos universais. Ambas as estratégias procuram analisar a sentença "a é $F$ ". Rodriguez-Pereyra propõe investigar qual o truthmaker dessa sentença, enquanto o nominalista de avestruz propõe analisar o comprometimento da sentença em questão. Este argumenta que existe uma boa teoria semântica para lidar com "a é F", que seria o critério quineano. Quando se comparam as duas abordagens, a abordagem do comprometimento ontológico parece ter uma nítida vantagem. Realismo, Nominalismo de Classe, Nominalismo de Semelhança e a Teoria de Tropos podem ser formulados como teorias de truthmakers. Não podemos decidir quais são as categorias ontológicas fundamentais apenas utilizando tal abordagem. E, por conta disso, não podemos decidir se devemos aceitar universais, tropos ou apenas particulares concretos (IMAGUIRE, 2014, p.

ALENCAR, Valdetonio Pereira de. Uma análise do nominalismo de avestruz. Griot : Revista de Filosofia, 
184-185). Na abordagem do comprometimento ontológico, precisamos postular apenas particulares concretos.

A linha principal de argumentação do nominalista de avestruz consiste em apontar que nenhuma das soluções relacionais para o problema dos universais é bem sucedida em explanar a relação que cada uma postula para expor o fato de $a \operatorname{ser} F$. A posição padrão do nominalista de avestruz consiste em defender que soluções relacionais sofrem do problema do regresso. Trataremos desse problema na próxima seção.

Armstrong (2007, p. 170) indica duas questões interessantes contra o Nominalismo de Avestruz. Em primeiro lugar, esta posição concentra esforços em mostrar que o problema do One Over Many pode ser superado sem a necessidade de postular universais. Contudo, vários nominalistas de avestruz concordam que talvez tenhamos que postular universais no final das contas por outros motivos, como por conta das predicações de segunda ordem. (DEVITT, 2010, p. 19; van CLEVE, 1994, p. 590; IMAGUIRE, 2014, p. 184). Se tivermos que postular universais, então uma solução relacional terá que ser usada. $O$ nominalista de avestruz poderia responder que não há solução para o problema dos universais sem problemas e que, mesmo não tendo como solucionar o problema das predicações de segunda ordem no momento, isso não implica que esse problema constitua uma refutação definitiva do Nominalismo de Avestruz.

Em segundo lugar, Armstrong (2007, p. 166) argumenta que talvez haja alternativas mais satisfatórias de fornecer uma análise semântica de "a é F". Por exemplo, uma teoria semântica alternativa que postule universais. Devitt simplesmente não exclui essa possibilidade ${ }^{4}$. Quine não teria uma reposta final para este problema. Ele acreditava que a preferência por rejeitar entidades abstratas, como universais, era uma questão de intuição filosófica ${ }^{5}$. Para ele, parece ser bastante intuitivo que devemos aceitar a teoria semântica que se comprometa com uma ontologia mais econômica. Para um nominalista, esta resposta é adequada. Com quanto menos tipos de entidades nos comprometermos, menor a chance de nossa teoria estar errada.

Outro problema concerne ao critério de compromisso ontológico. Vimos que o nominalista de avestruz utiliza o critério quantificacional de Quine: ser é ser um valor de uma variável. Argumento que o critério de Quine não é um critério ontológico. A rigor, isso não era para surpreender, pois esse critério concerne ao que uma teoria diz que há. Se duas teorias discordam sobre o que existe, o critério de Quine apenas indicaria a implicação existencial de cada teoria, isto é, as entidades que poderiam substituir a variável na fórmula quineana. Isso me parece bastante claro com relação às teorias científicas. $O$ nominalista de avestruz poderia

\footnotetext{
${ }^{4}$ Este problema levantado por Armstrong é semelhante aos problemas levantados por Mellor e Oliver (1997) e por Alston (1958). Temos a sentença "a é F" e temos a sua paráfrase "há um x tal que "a" designa x e "F" aplicase a x". A partir de outras teorias semânticas, poderíamos construir outras paráfrases. Essas paráfrases poderiam ter compromissos ontológicos diferentes da paráfrase quineana. Não há um argumento para decidir quando uma sentença possui um compromisso ontológico aparente de quando possui um compromisso ontológico real. Se a sentença original "a é F" se compromete com universais, por que precisamos de uma paráfrase na qual não se postula de universais? E, se precisamos parafrasear a sentença em questão, por que escolher justamente uma paráfrase que não postula universais?

${ }_{5}$ Para uma resposta alternativa a essa questão baseada na noção de grounding, cf. Imaguire (2014).
}

ALENCAR, Valdetonio Pereira de. Uma análise do nominalismo de avestruz. Griot : Revista de Filosofia, Amargosa-BA, v.18, n.2, p.435-447, dezembro, 2018. 
argumentar que isso também ocorre com teorias ontológicas. O Realismo e a Teoria de Tropos postulam outras entidades que não são particulares concretos para analisar propriedades. Contudo, segundo o nominalista de avestruz, universais e tropos não devem ser postulados, pois as variáveis podem ser substituídas apenas por particulares concretos. É fato que teorias se comprometem com particulares concretos. A noção de particular concreto, contudo, está sujeita a debate. O Nominalismo de Avestruz, assim como o Nominalismo Tradicional em geral, considera essas entidades não analisáveis. De maneira diferente, o Realismo e a Teoria de Tropos consideram que podemos analisar essa categoria ontológica em algo mais fundamental, sejam universais, sejam tropos. Assim, o critério quantificacional de Quine é perfeitamente compatível com a tese de que particulares concretos possam ser analisados. Esse critério assevera que qualquer teoria ontológica compromete-se com particulares concretos. Particulares concretos constituem uma categoria ontológica, mas nem todas as teorias ontológicas consideram que essa seja uma categoria ontológica fundamental. Assim, algumas teorias consideram que particulares concretos podem ser reduzidos a outras categorias ontológicas fundamentais. Existem, pelo menos, cinco maneiras de lidar com particulares concretos:

(1) Nominalismo Tradicional (incluindo o Nominalismo de Avestruz): particulares concretos não são analisáveis, isto é, eles constituem uma categoria ontológica fundamental.

(2) Realismo 1: particulares concretos são constituídos por um feixe de universais. Universais constituem a categoria ontológica fundamental.

(3) Realismo 2: particulares concretos são constituídos por um substrato e universais. Universais inerem nesses substratos. Substrato e universais são categorias ontológicas fundamentais.

(4) Teoria de Tropos Pura: particulares concretos são constituídos por um feixe de tropos. Tropos constituem a categoria ontológica fundamental.

(5) Teoria de Tropos Kernel: particulares concretos são constituídos por um substrato e tropos. Substrato e tropos são categorias ontológicas fundamentais.

O critério quantificacional de Quine indicaria que teorias ontológicas comprometem-se com particulares concretos. Como essas entidades devem ser analisadas? Qual das opções acima deve ser tida como verdadeira? A essas questões, o critério de Quine não pode responder ${ }^{6}$. Esse critério simplesmente não pode resolver disputas ontológicas. Quine estava certo: comprometemo-nos ontologicamente com particulares concretos. Se esses particulares concretos são tropos, universais ou qualquer outra teoria de particulares, isso é algo que se encontra além do critério quineano.

\footnotetext{
${ }^{6}$ É fato que Quine não pretendia solucionar questões ontológicas da maneira como o problema dos universais foi colocado a partir de Armstrong. Ontologia, para Quine, é algo interno de uma teoria. Existir particulares ou universais não constitui necessariamente um fato objetivo do mundo. Existência é entendida como aquilo que nossos esquemas conceituais (através das nossas teorias científicas) postulam. Como Quine possui uma postura antirrealista em epistemologia, a questão ontológica deve ser reduzida a uma questão epistemológica de como descrevemos o mundo.
}

ALENCAR, Valdetonio Pereira de. Uma análise do nominalismo de avestruz. Griot : Revista de Filosofia, Amargosa-BA, v.18, n.2, p.435-447, dezembro, 2018. 


\section{O problema do regresso}

Quando o nominalista de avestruz analisa soluções relacionais para o problema dos universais ${ }^{7}$, todas elas possuiriam o esquema:

(E) $a$ é $F$ porque $a$ está em uma relação $R \operatorname{com} \mathrm{x}$.

Para o nominalista de avestruz, o ponto central consiste em chamar atenção para o seguinte aspecto: soluções relacionais analisam o fato de $a$ ser $F$ através de (E). Por que devemos analisar esse fato, mas não podemos analisar o fato de a está em uma relação $R$ com $x$ ? Por que esse fato é fundamental? Por que não considerar a é $F$ como um fato fundamental? Aparentemente, as soluções relacionais não possuem uma resposta adequada para este problema. Estas soluções não poderiam analisar o fato de a está em uma relação $R$ com $x$ sem cair em um regresso ao infinito. Nesta seção, analiso se as soluções relacionais para o problema do regresso são insatisfatórias. Como o meu objetivo neste artigo é analisar o Nominalismo de Avestruz, não é necessário analisar se todas as soluções para o problema dos universais sofrem deste problema.

O Nominalismo de Classe postula a relação $x$ pertence a y na análise (3). Seja $F$ uma propriedade que apenas os particulares concretos $a$ e $b$ possuem. Assim, $a$ é $F$ porque $a$ pertence à classe dos Fs. Não há nenhuma razão aparente para não analisar o fato de a pertencer à classe dos $\{a, b\}$. Este fato seria analisado da seguinte maneira. $\mathrm{O}$ par ordenado $(\mathbf{a},\{\mathbf{a}, \mathbf{b}\})$ pertence* à classe $\{(\mathbf{a},\{\mathbf{a}, \mathbf{b}\}),(\mathbf{b},\{\mathbf{a}, \mathbf{b}\})\}$. Esse fato, por sua vez, deveria ser analisado, pois foi postulada uma nova relação pertencer*. Evidentemente, geraríamos um regresso infinito. Este argumento pode, entretanto, ser desafiado. Não devemos perder de vista que soluções para o problema dos universais são análises ontológicas. $O$ nominalista de classe vai defender que o fato $a$ é $F$ é composto apenas do particular concreto $a$ e do particular abstrato a classe dos Fs. Dadas essas duas entidades, não acredito que seja necessário nada além delas para compor o fato de a pertencer à classe dos Fs. Faz parte da definição da classe $\{a, b\}$ que o particular $a$ pertença a ela. Não parece haver qualquer adição ôntica quando afirmamos que $a$ pertence à classe $\{\mathbf{a}, \mathbf{b}\}$. Estamos apenas explicitando uma definição. Contudo, resta uma questão: a classe $\{(\mathbf{a},\{\mathbf{a}, \mathbf{b}\}),(\mathbf{b},\{\mathbf{a}, \mathbf{b}\})\}$ parece definir corretamente a relação de pertencer $a$. Se essa relação não introduz nada ontologicamente, como podemos encontrar uma classe que parece expressá-la corretamente? O Nominalismo de Classe sustenta que nem todas as classes são naturais. Classes são bem mais abundantes do que as propriedades escassas. Assim, poderia ser defendido que a classe acima não é natural e que ela não precisa ser introduzida para explanar o fato de a pertencer à classe dos $\{a, b\} . O$ particular $a$ e a classe $\{\mathbf{a}, \mathbf{b}\}$ são suficientes para compor ontologicamente esse fato. Na literatura sobre Nominalismo, existem várias razões para rejeitar o Nominalismo de Classe. Contudo, o problema do regresso não é uma delas.

A solução realista constitui o foco da crítica do Nominalismo de Avestruz. $\mathrm{O}$ particular $a$ é $F$ porque $a$ é uma instância de $F$. Nada impede que não devamos analisar o fato de a ser uma instância de $F$. Se o realista analisou a propriedade $F$, por que ele não deveria analisar a relação de instanciação? Se o realista analisasse essa

${ }^{7}$ Em geral, o nominalista de avestruz aponta o problema do regresso no Realismo e no Nominalismo de Tradicional.

ALENCAR, Valdetonio Pereira de. Uma análise do nominalismo de avestruz. Griot : Revista de Filosofia, 
relação através do seu esquema de análise (5), teríamos a seguinte análise: $a$ é uma instância de $F$ porque $a$ instancia* a instanciação de $F$. Devemos ter cuidado se essa introdução de instância* constitui alguma adição ôntica. A questão é semelhante à do Nominalismo de Classe: o particular $a$ e o universal $F$ são suficientes para compor o fato a é uma instância $F$ ? Infelizmente, a situação não é a mesma do Nominalismo de Classe. Não faz parte da definição do universal $F$ que o particular $a$ o instancie. Assim, parece que, além de existirem $a$ e $F$, é necessário que esses dois elementos estejam relacionados. Assim, precisamos da relação de instanciação para compor o fato a é uma instância de $F$. Isso geraria o regresso, como o próprio Armstrong admite (1974, p. 197).

Nem toda forma de realismo pode ser refutada pelo argumento do regresso. $\mathrm{O}$ problema do regresso provavelmente refuta o Realismo ante rem, que postula particulares e universais. Para alguém que defende o Realismo in re, a situação não é tão simples. Existem duas espécies dessa forma de Realismo. Há a versão de feixes e há a versão de substrato. A versão de feixes poderia defender que você não precisa de uma relação de instanciação para compor o fato a é $F$. Esse fato seria composto por um feixe de universais in re copresentes. Como copresença é uma noção meramente composicional - pode até ser entendida como mereológica - não haveria necessidade de postular qualquer relação e não haveria, portanto, qualquer regresso. Contudo, ainda é possível argumentar que admitir a relação de copresença gera um regresso. Isso parece um tema aberto na literatura. Parece-me que, nesse caso, o ônus da prova é do nominalista de avestruz. A versão do Realismo in re que postula substrato não possui uma saída tão simples. Armstrong, que defende essa forma de Realismo, possui uma solução inusitada para o problema do regresso. Ele defende uma forma não relacional de Realismo in re (ARMSTRONG, 1978, p. 107). Como, nessa forma de Realismo, os universais só têm existência nos particulares concretos, ele entende que um feixe de universais compõe, juntamente ao substrato, um particular concreto. Eles formam uma unidade na qual os elementos se relacionam apenas no sentido de comporem os mesmos particulares concretos. Essa maneira de composição não parece implicar uma adição ôntica. No entanto, como ocorreria essa composição? Particulares e universais não teriam que se relacionar de alguma maneira?

$\mathrm{O}$ argumento do regresso apenas refuta o Realismo ante rem. Esse argumento não parece refutar a versão de feixes do Realismo in Re. Com relação à solução de Armstrong, ela talvez não seja completamente adequada. Não é óbvio, contudo, que ele não possa recorrer a uma noção de composicionalidade que seja ontologicamente neutra.

\section{O problema dos Truthmakers}

Segundo Rodriguez-Pereyra, as principais soluções para o problema dos universais podem ser formuladas como teorias de truthmakers. Haveria, contudo, pelo menos uma exceção: o Nominalismo de Avestruz. Assim, ele analisa se essa forma de nominalismo é sustentável em uma abordagem de truthmakers. Na interpretação de Rodriguez-Pereyra, esse nominalismo teria que defender que o truthmaker de uma sentença da forma "a é $F$ " é apenas o particular $a$, pois aquela

ALENCAR, Valdetonio Pereira de. Uma análise do nominalismo de avestruz. Griot : Revista de Filosofia, 
sentença compromete-se ontologicamente apenas com esse particular. Como sentenças da forma "a é F" podem ser contingentemente verdadeiras, o objeto a pode não satisfazer a condição necessária para algo ser um truthmaker. Se a fosse o truthmaker de "a é F", então "a existe" implicaria "a é F". Como existem mundos

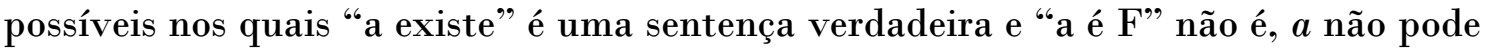
ser o que torna essa sentença verdadeira. Rodriguez-Pereyra considera (2002, p. 44) que este não seria um problema tão grave, pois o Nominalismo de Avestruz poderia recorrer ao Realismo Modal. Como todo particular existe em um único mundo possível, no mundo em que o particular $a$ existe, ele possui a propriedade $F$. Assim, essa forma de nominalismo poderia satisfazer a condição necessária para uma entidade ser um truthmaker. Como essa condição é apenas necessária, um problema é que não haveria, segundo o autor, nenhuma razão suficiente para que a entidade $a$ fosse o truthmaker da sentença "a é F".

Outro problema que escaparia ao nominalista de avestruz concerne à multiplicidade de propriedades. Não parece intuitivo que sentenças diferentes da forma "a é F" e "a é G" tenham os mesmos truthmakers. Tomem-se:

(1) Esta mesa é dura.

(2) Esta mesa é colorida.

A versão de truthmaking do Nominalismo de Avestruz indicaria que (1) e (2) possuiriam o mesmo truthmaker: a mesa em questão. Parece evidente que não pode ser a mesma coisa que torna esta mesa dura a que a torna também colorida. Assim, a multiplicidade de propriedades que um objeto possui não seria corretamente explanada por essa forma de nominalismo. Nesse aspecto, o problema dos universais poderia ser considerado o problema de explanar como o mesmo objeto pode ter diferentes propriedades (many over one). Enquanto teoria de truthmaking, o Nominalismo de Avestruz é insatisfatório. Por isso, deve ser descartado das soluções para o problema dos universais.

Melia (2005, p. 69) defende uma visão avestruz com relação aos truthmakers de sentenças da forma "a é $F$ ". Ele pensa que nós temos uma boa compreensão de como predicados funcionam. $O$ autor pretende, assim, separar a função dos nomes da função dos predicados. Nomes denotam particulares concretos. Predicados descrevem essas entidades. E, contrariamente ao que Armstrong pensava, descrever é uma função séria. Assim, temos uma boa compreensão de como predicados descrevem particulares sem precisar pensar que eles devam comprometer-se ontologicamente com qualquer outra entidade em adição aos particulares concretos. De forma semelhante, temos uma boa compreensão de como sentenças inteiras podem ser verdadeiras sem precisarem de comprometimento ontológico. "The insistence that truthmakers must be postulated to account for truths seems to the sensible nominalist at best unmotivated, at worst based on a confusion about the semantic function of sentences" (MELIA, 2005, p. 69). O argumento do autor consiste em considerar que sentenças possuem uma função semântica mais próxima dos predicados do que dos nomes, isto é, sentenças não denotam. Sentenças apenas possuem uma função descritiva semelhante à função dos predicados. Por possuir essa função semântica, não há motivação para postular truthmakers para sentenças da forma "a é F".

ALENCAR, Valdetonio Pereira de. Uma análise do nominalismo de avestruz. Griot : Revista de Filosofia, 
Entretanto, Melia considera que o nominalista de avestruz precisa fornecer truthmakers para algumas sentenças especiais:

(1) Há uma propriedade que você e eu compartilhamos.

(2) Há uma cor que $a$ e $b$ possuem em comum.

(3) Há pelo menos três propriedades em $\boldsymbol{a}$ e $\boldsymbol{b}$ que ambos possuem.

Assim, a ser vermelho e b ser vermelho constituem os truthmakers da sentença (2), por exemplo. Qual o truthmaker das sentenças "a é vermelho" e "b é vermelho"? Segundo Melia, devemos ter uma postura avestruz com relação a essa questão. Essas sentenças não possuem truthmaker, pois sentenças possuem função semântica semelhante à dos predicados.

Meu interesse não se encontra na análise das sentenças (1), (2) e (3). O problema dos universais precisa também fornecer uma análise ontológica de fatos como a é $F$. Assim, se a abordagem de truthmaking pode ajudar a solucionar esse problema, considero que se deve concentrar na análise dos truthmakers de sentenças da forma "a é F". A proposta de Melia não é adequada para sentenças desse tipo. A primeira concerne à análise de Melia. Considero que a pergunta pelo truthmaker de sentenças da forma "a é F" não implica em haver algum equívoco na função semântica. Melia parte de uma concepção clara de qual é a função semântica dos nomes, dos predicados e das sentenças. "Names denote things, but predicates describe them and this is a serious role" (MELIA, 2005, p.68). Um problema é que, em filosofia da linguagem, existe disputa sobre a função semântica dos nomes, dos predicados e das sentenças. Nomes denotam coisas? Mill, Kripke e seus seguidores responderiam afirmativamente. Russell e Searle negariam que nomes da linguagem natural denotam coisas. Mas o ponto de Melia diz respeito às sentenças. Ele acredita que a motivação para a ideia de truthmaker origina-se de uma concepção equivocada da função semântica das sentenças. Qual a função semântica das sentenças? Essa é a questão central da filosofia da linguagem. Desde o primeiro Wittgenstein, pelo menos, a filosofia analítica da linguagem considera que sentenças declarativas não denotam. Não é clara a relação que Melia estabelece entre a função semântica das sentenças e a falta de motivação para a ideia de truthmaker. Aparentemente, ele considera que requerer um truthmaker para toda sentença implica que a sentença tenha uma função denotativa. Essa relação, contudo, não é correta. Interessante que na filosofia contemporânea a ideia truthmaker foi introduzida por Russell na sua fase do atomismo lógico e é uma noção definível na estrutura do Tractatus de Wittgenstein. Para este, sentenças não possuem referência, apenas sentido ou significado. Proposições constituem o significado das sentenças. E o sentido de uma proposição consiste em suas condições de verdade. $\mathrm{O}$ mundo é composto por fatos, e esses fatos tornam as proposições verdadeiras ou falsas. Apesar disso, proposições não denotam fatos. Proposições expressam uma possibilidade (um "estado de coisas", na terminologia do Tractatus). Assim, perguntar pelo truthmaker de uma sentença não implica que estamos atribuindo uma função semântica denotativa às sentenças declarativas. Pelo contrário, se essas sentenças são verdadeiras ou falsas e, caso se use uma concepção realista de verdade, parece completamente legítimo buscar saber qual o truthmaker de sentenças da forma "a é F".

Rodriguez-Pereyra defende que o Nominalismo de Avestruz não se sustenta se formulado enquanto uma teoria de truthmakers. A crítica de Rodriguez-Pereyra

ALENCAR, Valdetonio Pereira de. Uma análise do nominalismo de avestruz. Griot : Revista de Filosofia, 
pode ser formulada sem utilizar a noção de truthmaker. $O$ problema dos universais consiste em fornecer uma análise ontológica de fato da forma $a$ é $F$. Para o nominalista de avestruz, não seria possível diferenciar ontologicamente estes dois fatos: $a$ é $F$ e $a$ é $G$. Esses dois fatos seriam compostos apenas pela mesma entidade, a saber, o particular concreto $a$. Segundo van Cleve, "One could hold that the fact that $a$ is $F$ has $a$ as its sole constituent, and that the difference between this fact and the fact that $a$ is $G$ is not a difference in their constituents" (1994, p. 589). Ele, contudo, não fornece um argumento a favor dessa tese. Como dois fatos com os mesmos constituintes ontológicos podem ser diferentes? Uma resposta do nominalista seria que o particular a possui, de maneira primitiva, as propriedades $F$ e $G$. Isso já seria mais do que suficiente para compor os seguintes fatos: $a$ é $F$ e $a$ é $G$. Um problema para o qual Rodriguez-Pereyra chama atenção é que as propriedades $F$ e $G$ podem não ser propriedades essenciais do particular $a$. Assim, a mera existência desse particular não implica que os fatos em questão existam. Para resolver esse problema, o nominalista de avestruz teria que admitir o Realismo Modal e sua ontologia de possibilia.

Um argumento, que reforça (mas não é definitivo contra o Nominalismo de Avestruz) que os fatos $a$ é $F$ e $a$ é $G$ são ontologicamente diferentes, consistiria em comparar a análise do Nominalismo de Avestruz à análise de outras soluções para o problema dos universais (MELO, 2013, p. 94). Os realistas diferenciam esses fatos na medida em que o particular $a$ instancia os universais $F$ e $G$. Logo, os fatos acima seriam ontologicamente distintos. O nominalista de classe irá recorrer a classes de possibilia. $\mathrm{O}$ particular a é $F$ porque a pertence à classe dos $\mathrm{Fs}$ (possibilia) e a é $G \mathrm{em}$ virtude de $a$ pertencer à classe dos Gs (possibilia). Os fatos acima também são diferenciados no Nominalismo de Classe ${ }^{8}$. O Nominalismo de Semelhança também pode diferenciar ontologicamente esses dois fatos: $O$ particular a é $F$ em virtude de $a$ ser semelhante a todos os Fs (possibilia) e $a$ é $G$ em virtude de $a$ ser semelhante a todos os Gs (possibilia). Assim, todas as soluções para o problema dos universais conseguem expressar a intuição de que os fatos em questão são ontologicamente diferentes, com exceção do Nominalismo de Avestruz.

\section{Considerações finais}

Neste artigo, analisei criticamente o Nominalismo de Avestruz. Em um primeiro momento, apresentei as teses fundamentais dessa teoria. Apesar de argumentar que essa teoria não considera o problema dos universais um pseudoproblema, levanto uma série de problemas contra essa posição. Em geral, levantei três críticas principais. A primeira crítica foi de tipo interna. Argumentei que o critério quantificacional apresenta problemas, se interpretado como critério ontológico. A segunda crítica também foi interna. O Nominalismo possui como um dos eixos centrais de sua argumentação o problema do regresso. Argumentei, contudo, que esse problema não afeta todas as soluções relacionais. Por último, analisei uma crítica externa. Analisei a resposta de Melia ao problema dos

\footnotetext{
${ }^{8}$ Se não fosse o problema da coextensionalidade, o Nominalismo de Classe não precisaria inflacionar a sua ontologia com o Realismo Modal. Neste aspecto, seria interessante, para essa forma de Nominalismo, que $a$ é $F$ e a é $G$ pudessem constituir o mesmo fato de um ponto de vista ontológico.
}

ALENCAR, Valdetonio Pereira de. Uma análise do nominalismo de avestruz. Griot : Revista de Filosofia, 
truthmakers, levantado por Rodriguez-Pereyra. Portanto, considero que esta solução para o problema dos universais possui algumas deficiências. 


\section{Referências}

ALSTON, William. Ontological Commitments. Philosophical studies, v. 9, p. 8-17, 1958.

ARMSTRONG, D. M. Infinite Regress Arguments and the Problem of Universals. Australasian Journal of Philosophy, 52, p. 191-201, 1974.

. A theory of universals: volume I: nominalism and realism. Cambridge:

Cambridge University Press, 1978a.

Against 'Ostrich' Nominalism: A Reply to Michael Devitt (1980). In: BEEBEE, Helen e DODD, Julia (eds.). Reading metaphysics. Oxford, Blackwell Publishing, 2007.

1989.

Universals: an opinionated introduction. San Francisco: Westview Press,

DEVITT, Michael. 'Ostrich Nominalism' or 'Mirage Realism?' (1980). In: Putting Metaphysics First: Essays on Metaphysics and Epistemology. Oxford: Oxford University Press, 2010.

IMAGUIRE, Guido. In Defense of Quine's Ostrich Nominalism. Grazer Philosophische Studien, v. 89, p. 185-203, 2014

MELIA, Joseph. Truthmaking Without Truthmakers. In: BEEBEE, Helen e DODD, Julia (eds.). Truthmakers: The Contemporary Debate. Oxford: Clarendon Press, 2005.

MELLOR, David e OLIVER, Alex. Properties. Oxford: Oxford University Press, 1997.

MELO, Thiago Xavier de. O problema dos universais como um problema de categorização ontológica. 107f. Dissertação de Mestrado - Universidade Federal do Rio de Janeiro, 2013.

PEACOCK, Howard. What's Wrong with Ostrich Nominalism? Philosophical Papers, v. 38 (2), p. 183-217, 2009.

RODRIGUEZ-PEREYRA, G. What is the Problem of Universals? Mind. vol. 109, p. 255-273, abril 2000.

. Resemblance nominalism: A solution to the Problem of Universals. Oxford: Oxford University Press, 2002.

QUINE, Willard van Orman. On Universals. The Journal of Symbolic Logic, v. 12, p. 74-84, set. 1947.

On What There Is. In: From a logical point of view. New York: Harper torchbooks, 1961

VAN CLEVE, James. Predication Without Universals? A Fling with Ostrich Nominalism. Philosophy and Phenomenological Research, v. 54 (3), p. 577-590, 1994.

Autor(a) para correspondência: Valdetonio Pereira de Alencar, Universidade Federal do Cariri, R. Ten. Raimundo Rocha, s/n, Cidade Universitária, CEP 63048-080, Juazeiro do Norte - CE, Brasil. valdetonio.alencar@ufca.edu.br 